\title{
Artigos
}

\section{Contribuição da interseccionalidade na compreensão da saúde-doença-cuidado de homens jovens em contextos de pobreza urbana}

The contribution of intersectionality on understanding young men's healthdisease and care in contexts of urban poverty (abstract: p. 15)

Contribución de la interseccionalidad en la comprensión de la salud-enfermedad y el cuidado de hombres jóvenes en contextos de pobreza urbana (resumen: p. 15)

Elda de Oliveira ${ }^{(a)}$
<eldade@usp.br> (D)

Marcia Thereza Couto(b)

<marthet@usp.br>

Marco Antônio Alves Separavich ${ }^{(\mathrm{c})}$

<mseparavich@hotmail.com>

Olinda do Carmo Luiz ${ }^{(\mathrm{d})}$

<olinda@usp.br>

\author{
(a) Pós-graduanda do \\ Departamento de Medicina \\ Preventiva (pós-doutorado), \\ Faculdade de Medicina, \\ Universidade de São Paulo. \\ Avenida Dr. Arnaldo, 455, $2^{\circ}$ \\ andar, sala 2165, Cerqueira \\ César. São Paulo, SP, Brasil. \\ 01246-903. \\ (b, d) Departamento de Medicina \\ Preventiva e Programa de Pós- \\ Graduação em Saúde Coletiva, \\ Faculdade de Medicina, \\ Universidade de São Paulo. \\ São Paulo, SP, Brasil. \\ (c) Grupo de Estudo e Pesquisa \\ em Saúde, Interseccionalidade \\ e Marcadores Sociais da \\ Diferença, Faculdade de \\ Medicina, Universidade de São \\ Paulo, São Paulo, Brasil.
}

$\mathrm{O}$ artigo analisa as experiências vividas por homens jovens da periferia a respeito das desigualdades sociais e seus impactos no processo de produção da saúde-doença-cuidado. O material empírico que dá suporte à análise interseccional foi produzido pela metodologia qualitativa da pesquisa-ação, a partir de oficinas, técnica grupal em investigações participativas. Participaram 21 homens e cinco mulheres, com idades entre 15 e 17 anos, que frequentavam escola pública da região periférica do município de São Paulo (SP), Brasil. Os resultados salientam que os homens jovens compartilham desvantagens de raça/cor, classe, gênero e geração que se entrelaçam e atuam de forma complexa na produção das iniquidades sociais e de saúde. Portanto, análises que reduzem as desigualdades a um único sistema classificatório - seja classe, gênero ou raça/cor - são inadequadas para compreender as várias dimensões que as compõem.

Palavras-chave: Interseccionalidade. Adolescente. Masculinidade. Saúde pública. Iniquidade social.

Oliveira E, Couto MT, Separavich MAA, Luiz OC. Contribuição da interseccionalidade na compreensão da saúdedoença-cuidado de homens jovens em contextos de pobreza urbana. Interface (Botucatu). 2020; 24: e180736 https://doi.org/10.1590/Interface.180736 


\section{Introdução}

O Brasil é um dos países que apresenta acentuada desigualdade social, aparecendo em décimo lugar no ranking dos países mais desiguais do mundo, entre mais de 143 países $^{1}$. As iniquidades sociais experienciadas por segmentos populacionais específicos, como os homens jovens negros e de periferia, representam uma preocupação no cenário local e global, pois a injustiça social está matando em escala mundial, devido às condiçóes em que as pessoas nascem, vivem, trabalham e envelhecem, tendo em vista que desigualdades econômicas e sociais se expressam em aspectos relacionados ao processo saúde-adoecimento ${ }^{2}$.

Para compreender e enfrentar as iniquidades em saúde, várias teorias e abordagens vêm sendo utilizadas, como a teoria da determinação social do processo saúde-doença. Essa teoria considera os determinantes sociais, tais como os fatores sociais, econômicos, culturais, étnicos/raciais, psicológicos e comportamentais que influenciam a ocorrência de problemas de saúde em grupos e populaçóes ${ }^{2}$. Embora muito expressiva, essa teoria tem recentemente buscado dialogar com outras perspectivas que, aparentemente próximas, diferenciam-se por não enfatizarem as determinaçốes econômicas frente aos diversos aspectos de desigualdades que hoje são reconhecidos como marcadores sociais da diferença, incluíndo gênero, sexualidade, geração, além dos já tradicionais aspectos de classe social e raça/cor. Assim, a abordagem da interseccionalidade inaugura uma nova vertente teórico-metodológica que busca analisar a complexidade e irredutibilidade de um marcador social da diferença sobre o outro. Os marcadores são definidos como construçóes sociais anteriores à existência dos sujeitos, os quais se articulam produzindo maiores ou menores inclusões ou exclusôes, dependendo, para tanto, de uma série de fatores sociais.

Nas investigações em saúde, têm sido raros os estudos que se propóem a incorporar nas análises a complexidade com que esses fatores econômicos, geracionais, de gênero e de raça/cor incidem nos corpos dos sujeitos e em suas experiências ${ }^{3}$, o que tem gerado lacunas significativas. Essas lacunas, no tocante à compreensão total das causas das desigualdades, têm sido alvo de investimento teórico-metodológico por pesquisadores que utilizam a abordagem da interseccionalidade ${ }^{4}$ na ampliação da compreensão das iniquidades, pela possibilidade de incluir as formas complexas pelas quais os marcadores sociais se relacionam e se reforçam mutuamente.

Segundo Hankivsky ${ }^{5,6}$ e Bowleg7, a interseccionalidade é promissora, pois sublinha que "o todo" da discriminação sofrida por uma pessoa é complexo e maior que a soma das partes. Por conseguinte, pode-se considerar que a interseccionalidade é uma abordagem teórica e metodológica para compreender as desigualdades sociais e propor açôes políticas para combatê-las.

A abordagem interseccional considera que nenhuma diferença deve ser reduzida a um único sistema classificatório, a fim de não perder a força da articulação que propõe para os marcadores sociais da diferença ${ }^{8}$, para assim compreender as várias dimensões das desigualdades que conformam e influenciam as posiçôes sociais, as experiências dos sujeitos e as relaçóes de poder que estabelecem na sociedade ${ }^{9}$. No atual debate teórico-metodológico interseccional, tem merecido atenção o questionamento da exigência (ou não) de se trabalhar a tríade gênero, raça e classe em articulação, bem como quais e quantos outros marcadores sociais da diferença podem ser acionados nas análises 
empíricas de temas e objetos de estudos ${ }^{10}$. Outro foco do debate tem sido compreender como um marcador se conecta a outro e como se potencializam mutuamente.

A utilização da abordagem interseccional na saúde congrega a perspectiva da equidade e justiça social. O debate, posto desde a primeira década do atual século, considera os arranjos estruturais dos marcadores sociais da diferença, buscando ir além do reconhecimento da natureza multidimensional das iniquidades em saúde. Além disso, propóe a elaboração de desenhos de pesquisa e modelos de análise capazes de medir e analisar, simultaneamente, a multidimensionalidade dos marcadores sociais da diferença em processos de iniquidades em saúde ${ }^{4,9}$.

Assim como em outros campos disciplinares ${ }^{10}$, a produção das análises interseccionais na saúde se utiliza das abordagens quantitativa e, principalmente, qualitativa'. Para tanto, existem diferentes perspectivas para fazer a articulação das diferenciaçốes, que variam na forma como são pensadas a diferença e o poder ${ }^{11}$.

Considerando as masculinidades como objeto central deste estudo, apoiamo-nos em autores que defendem que estas devem ser analisadas no cotidiano concreto e nas relaçôes sociais que os homens estabelecem ${ }^{12,13}$. A interseccionalidade potencializa a investigação das masculinidades, pois, a depender dos papéis que os sujeitos exercem no cotidiano, há consequências para a saúde ${ }^{4}$.

Nas investigações de saúde dos homens negros no Brasil, as questões de diversidade de pertencimento e reconhecimento de raça/cor permanecem pouco exploradas, assim como são esparsas as discussões acerca das dinâmicas das relações econômicas, sociais e comportamentais que os homens estabelecem entre seus pares e com as mulheres. Partindo da análise interseccional, na qual é impossível não levar em consideração as experiências e os saberes de grupos e indivíduos, e aplicando-a aos homens jovens situados em contextos periféricos na cidade de São Paulo (SP) - Brasil -, realizamos os seguintes questionamentos: de que modo os marcadores sociais da diferença como classe social, raça/cor e gênero reproduzem modos de vida próprios aos homens jovens? Como esses modos de vida, que se expressam nas experiências cotidianas, refletem sistemas interligados de desigualdades sociais com repercussóes no processo de produção da saúde, doença e cuidado?

O objetivo deste trabalho, portanto, é analisar as experiências vividas por homens jovens da periferia a respeito das desigualdades sociais e seus impactos no processo de produção da saúde-doença-cuidado à luz da articulação dos marcadores sociais da diferença, desde a perspectiva da interseccionalidade em diálogo com a determinação social do processo saúde-doença.

\section{Método}

O material empírico que dá suporte às análises deste estudo remontam à pesquisa qualitativa desenvolvida a partir da metodologia da pesquisa-ação emancipatória, que se fundamenta no método dialético ${ }^{14}$. O estudo original, conduzido nos meses de fevereiro a setembro de 2014, com recesso em junho e julho devido às férias escolares dos jovens e à Copa do Mundo, foi submetido, avaliado e aprovado pelo Comitê de Ética da instituição proponente, sob o parecer 1.897.327. 


\section{Participantes do estudo}

Participaram da investigação 21 homens e cinco mulheres jovens com idades entre 15 e 17 anos. Estes compóem a categoria social juventude. Para constituir essa categoria, toma-se o ambiente social, as identidades, o compartilhamento dos usos de linguagens e símbolos coletivos com os quais os jovens se identificam e se localizam no processo histórico; e os sistemas de classe, como os de raça e gênero ${ }^{15,16}$.

Os participantes frequentavam uma escola pública situada no distrito de Guaianases, São Paulo (SP), Brasil, que atende alunos do ensino fundamental e médio e educação para jovens e adultos (EJA). A escolha dessa região tem relação com o fato de que Guaianases é um território situado às margens da cidade de São Paulo, característico da área de periferia urbana onde se aprofundam as desigualdades espaciais da cidade ${ }^{17}$.

\section{Produção e organização dos dados}

A coleta dos dados primários foi realizada por meio de oficinas, técnica grupal de produção de dados em investigações participativas, com grupos de características homogêneas ${ }^{18}$. Foram realizadas 13 oficinas, cada uma com cerca de duas horas de duração. Foram utilizados vários recursos para incentivar e mediar a comunicação entre os jovens e com eles, como a aplicação de questionário; discussôes mediadas por filmes; desenhos em quadrinhos; colagens; encenações e outas produçôes artísticas; e comunicação em redes sociais. Todas as oficinas foram gravadas e filmadas pelos próprios jovens em momentos de apresentação de dramatizaçôes e de sínteses ${ }^{18}$. Em seguida, as gravaçôes foram transcritas na íntegra. O diário de campo foi uma técnica auxiliar de produção dos dados, tendo sido utilizado em todas as oficinas.

Quadro 1. Número de oficinas e de participantes; e distribuição dos jovens em cada oficina, de acordo com o sexo

\begin{tabular}{|c|c|c|c|}
\hline N. de oficinas & N. de participantes & Masculino & Feminino \\
\hline $1^{\circ}$ & 26 & 21 & 5 \\
\hline $2^{\circ}$ & 16 & 11 & 5 \\
\hline $3^{\circ}$ & 16 & 11 & 3 \\
\hline $4^{\circ}$ & 13 & 10 & 5 \\
\hline $5^{\circ}$ & 17 & 11 & 3 \\
\hline $6^{\circ}$ & 11 & 8 & 3 \\
\hline $7^{\circ}$ & 12 & 9 & 4 \\
\hline $8^{\circ}$ & 12 & 3 & 4 \\
\hline $9^{\circ}$ & 7 & 9 & 4 \\
\hline $10^{\circ}$ & 13 & 3 & 5 \\
\hline $11^{\circ}$ & 8 & 4 & 3 \\
\hline $12^{\circ}$ & 7 & 4 & 3 \\
\hline $13^{\circ}$ & 7 & & \\
\hline
\end{tabular}




\section{Análise dos dados}

No recorte de análise proposto neste artigo, avaliamos as falas dos homens jovens, embora no contexto da produção dessas falas estejam presentes as mulheres jovens por também participarem das oficinas. O material empírico referente aos homens jovens foram analisados à luz da perspectiva da interseccionalidade, segundo adaptação da proposta de Winker e Degele ${ }^{19}$. As autoras sugerem uma análise multinível, pois leva em consideração a construção da identidade, as representaçôes simbólicas e a estrutura social na qual os participantes estão imersos.

No estudo, seguiram-se quatro passos de Winker e Degele ${ }^{19}$, sem que se fixassem fronteiras rígidas entre eles. $\mathrm{O}$ passo 1 remete à identificação dos participantes no processo de reconhecer-se e diferenciar-se de outros sujeitos, trazendo luz às histórias dos jovens. O passo 2 identifica as representaçôes simbólicas do grupo, contemplando consensos e dissensos acerca das categorias de diferenciação para análise da construção de suas identidades, ao mesmo tempo em que se busca alcançar as representações hegemônicas dos sujeitos. Esse segundo passo tem como objetivo identificar todas as normas, valores e ideologias a que as pessoas se referem. O passo 3 busca estabelecer associações entre o nível das práticas e as representaçôes simbólicas que dão sentido às primeiras, com o propósito de alcançar normas e sentidos de negação e de afirmação de valores partilhados pelo grupo, buscando localizá-las frente à estrutura social. As categorias de diferenciação são alocadas nas categorias de raça/cor, gênero e classe social, intersectando-as. No passo 4, reúne-se a multiplicidade de categorias de diferenciação que são importantes para o grupo, as quais aparecem nos níveis da identidade, representação e estrutura social; é crucial descobrir as tematizaçóes mais importantes (que também podem atravessar os diferentes níveis) e seus entrelaços e conflitos. Nesse processo, identificou-se que a categoria de diferenciação principal do grupo é “direitos sociais”, já que esta atravessa os três níveis. A síntese interpretativa final foi realizada em consonância com outros estudos do segmento social em questão - homens jovens negros vivendo em contextos de periferia urbana.

\section{Resultados}

O primeiro passo proposto por Degele e Winker ${ }^{19}$ é a descrição da identificação dos participantes. A primeira marca de diferenciação social salientada foi habitarem na periferia; território marcado por privaçóes e carências das condiçóes materiais de existência e ausência do Estado, significando ausência dos direitos sociais.

A nossa realidade é gravidez na adolescência, a falta de água, assaltos, brigas, falta de moradias. Nós não temos incentivo à leitura, não temos espaço de lazer, tem bebidas e o funk. (Participante da oficina 2)

Nós temos um hospital em Guaianases e esse hospital não tem médicos e falta aparelhos. O posto de saúde, não tem nada naquele posto de saúde. Lá só serve para pegar remédio, nenezinhos tomar vacina, eles atendem se for grávida, mas pra gente demora muito, mas para grávida e idoso não demora [...]. (Participante da oficina 9) 
Buscando compreender a diferença do território de Guaianases com a área mais central de São Paulo, os jovens destacaram a "diferença de renda” e a "qualidade de vida”, o que gera diferentes necessidades. Essas noçôes como necessidades e falta se aprofundam ao apreendermos as respostas obtidas no questionário padronizado de autopreenchimento, composto por variáveis que possibilitam classificar as famílias dos participantes quanto à produção e consumo. Dos 12 jovens que responderam ao questionário, sete apontaram que as famílias eram chefiadas por mulheres; quanto ao preparo para o trabalho, quatro não possuíam cursos que os habilitassem para o trabalho; quanto ao vínculo empregatício, um estava desempregado e um fazia bicos; e algumas famílias recebiam auxílios do Estado via Programa Bolsa Família (PBF).

Os dados produzidos a partir das apresentaçôes teatrais e dos debates promovidos com os jovens e entre eles, descritos sistematicamente nos diários de campo, apontam que os participantes se autodenominam negros, não apenas pela cor da pele, mas também por habitarem a periferia. Afirmaram que a periferia é explorada e sofre discriminação social e racial e exemplificaram essa condição mencionando cenas do filme "Quanto vale ou é por quilo?", em que crianças brancas são pintadas de preto para representar crianças carentes da periferia a fim de receber donativos para Organizaçôes Não Governamentais (ONGs). Exemplificaram também citando políticos que, em tempo de eleição, aparecem na mídia oferecendo alimentos às crianças carentes, solicitando votos e prometendo mobilidade social.

O que estava acontecendo antigamente ainda acontece, ainda tem gente sendo explorada, com racismo, preconceito. (Participante da oficina 6)

O escravo não podia ser livre, mas ele podia ter comprado a liberdade dele, coisa que hoje em dia não acontece, você não pode estar comprando sua liberdade. (Participante da oficina 6)

Outra diferença, ressaltada pelos jovens, foi a questão da educação, sendo o acesso relativamente fácil, porém, com extrema dificuldade para a permanência e dedicação. Entre os participantes, dois abandonaram a escola para trabalhar, dois solicitaram transferência de escola para estudar à noite e dois estudavam e trabalhavam. Os jovens que permanecem na escola consideram que são poucos os que terão acesso aos bens produzidos socialmente, isto é, "um de um bilhão", sendo, portanto, privilégio de uns poucos "nerds".

[Mostra uma colagem de um jovem branco; acima do jovem, escrito: "Ele tem um bilhão de amigos”]. Isso aqui, de um bilhão de alunos, somente um é assim. Isso aqui está representando os alunos nerds, dedicados, que fazem tudo quando vão à escola [...]. (Participante da oficina 1 )

Considerando, ainda, as diferenciaçôes apreendidas no campo, há os bailes funk realizados nos espaços públicos periféricos, nos quais os homens jovens participantes são considerados “maloqueiros” por conta da participação. 
O funkeiro tem fama de ser assaltante, mas vai falar que só o funkeiro rouba? (Participante oficina 3)

Se você vê um menino voltando da escola com uma bolsa, você vai julgar o menino, ele é um menino bom, mas se você vê um menino saindo do baile funk, você vai dizer: esse moleque é maloqueiro, porque ele está no baile funk. Isso é um preconceito. (Participante oficina 3 )

Entretanto, nem todas as experiências são compartilhadas em unanimidade pelos jovens, principalmente em relação aos gostos musicais. As preferências variam entre gospel, rock, música clássica, rap, funk entre outras. Entre essas preferências, o funk é o que os une e, ao mesmo tempo, o que os afasta.

Você não pode gostar de rock, sertanejo. [...], mas se você gosta disso, você é isolado. [...]. Eu sou isolado no seu grupo que gosta de funk. (Participante da oficina 2)

Quando você vê um funkeiro é normal [na região], mas se você vê um roqueiro, vem aquele preconceito. Olha o cara ali, olha a calça rasgada. (Participante da oficina 2)

O rapé o som da periferia. [...]. O rapé mais realista. O rap fala mesmo as coisas, como da polícia, mas do que jeito que acontece mesmo. Às vezes, está na nossa cara e a gente não quer ver. Por isso que o povo parou de ouvir rap. Rap é a realidade do pobre, não só do pobre, mas da periferia, que é do pobre. (Participante da oficina 9)

Quando se trata da relação "nós” versus "eles”, em referência a grupos externos, as referências dissonantes são as de raça/cor, gênero e classe social, as quais apareceram nos níveis da identidade, representação simbólica e estrutura social. Para essa relação, foi trazido um artigo sobre os "rolezinhos", comparando-se um grupo de estudantes que comemorava a entrada na Universidade de São Paulo (USP), em um shopping de São Paulo, com os "rolezinhos" dos jovens da periferia, nos diferentes shoppings da cidade.

Os jovens do "rolezinho" da USP não foram expulsos do shopping e as lojas não foram fechadas. Em contrapartida, os jovens das periferias foram expulsos dos shoppings com abordagem policial, de forma violenta. As lojas foram fechadas e criou-se uma liminar proibindo jovens das periferias de entrarem em grupo nos shoppings centers. Na mídia, os "rolezinhos" das periferias foram mostrados como sendo ilegais e diversos meios de comunicação classificaram o evento como "baderna", "tumulto" e "quebra-quebra", realizado por "funkeiros".

É possível perceber que, para os jovens, todas as diferenças ressaltadas são pelo fato de os jovens da USP terem melhores condiçốes sociais e não serem negros pobres da periferia; logo, possuem o direito de ocupar os espaços das cidades. 
O rico pode ocupar o espaço, o pobre não. (Participante oficina 04)

Estamos falando de diferença de classe social. Quem faz USP é outro nível e quem não faz é ninguém. (Participante oficina 4)

[Em relação à mídia] Um desses que comentou disse que os que participam dos "rolezinhos" são negros e pessoas de baixa renda [...]. É errado ele falar desse jeito, porque só esse tipo de pessoal pode fazer isso [...]. (Participante oficina 4)

Essas proibições são repetidas no cotidiano dos participantes, coagindo o direito de ir e vir dos jovens e de participação social.

Eu estava descendo com um amigo meu e estava com a mochila da escola na frente. A polícia me parou e ficou perguntando: cadê, cadê os cachimbos, cadê o bagulho? (Participante da oficina 4)

Tenho um amigo que foi no "rolezinho", pegaram ele e tamparam o rosto dele, aí parece que ele estava badernando, só que tem foto no Facebook de que ele estava com as amigas, só que teve o tumulto e no meio da muvuca [...], pegaram ele e mostrou na mídia que ele causou aquilo tudo, sendo que não, ele foi lá pra se divertir com as amigas. (Participante da oficina 4)

É dentro desse contexto de contradiçôes, precariedades e exclusões que os homens jovens negros constroem suas identidades.

O lado positivo [dos “rolezinhos”] é que o jovem não vai mais ficar em casa, vai sair com os amigos, marcar encontro, esses negócios, agora se eu ficar em casa eu não vou saber da malandragem do mundo. (Participante da oficina 2)

No segundo passo, as representaçóes simbólicas de poder salientadas pelo grupo são a maconha, a moto barulhenta, o carro, a roupa de marca, o dinheiro e o cartão de credito, símbolos correlacionados ao "homem malandrão" e ao "homem rico".

Eu quero mostrar para as meninas que eu tenho uma moto, que eu tenho um carro. Quero mostrar que eu posso. Mas como a pessoa vai poder se aqui não tem recursos? (Participante da oficina 2)

[...]. Ele quer mostrar e dizer que é o bam bam bam porque está com o baseado na boca [...]. Eles [fumando maconha] sentem mais que os outros, sentiam um bam, bam bam. (Participante da oficina 2) 
Quase todo mundo usa a mesma roupa aqui, roupa de marca disso e daquilo.

(Participante da oficina 4)

Seguindo para terceiro passo, constata-se que é a partir das práticas e experiências cotidianas, principalmente nos espaços de socialização dos bailes funks, que os homens jovens negros pobres constroem suas masculinidades. Eles exibem seus corpos e os produtos que possuem como forma de poder. Essa performance desempenhada nos contextos locais favorece os processos de posicionamento hierárquico entre esses homens, estando nos níveis mais altos, por exemplo, aqueles que exibem os melhores produtos, símbolos de poder, diferenciando-se de outros homens jovens do território e facilitando inclusive as relações dos primeiros com as mulheres. A distinção entre eles se dá pela diferenciação de gênero e pelos bens materiais que empoderam suas masculinidades.

Porque no funk, se você não tiver nada, você não é nada. [...]. Agora, se um moleque passa com uma moto barulhenta... (Participante da oficina 2)

É no território que a performance das masculinidades dos jovens da periferia é atrelada às condiçôes socioeconômicas, à violência e ao aprisionamento, salientando a exclusão dos direitos socias.

Olha o que acontece em Guaianases, tem muito baile funk. No baile funk tem muitas drogas e álcool, com muitas drogas e álcool, tem muita violência policial, e com a violência policial, vem a nossa violência, porque nós também somos violentos, aí tem muita rejeição. (Participante da oficina 2)

Finalizando, com o quarto passo, identifica-se que esses jovens constroem suas identidades considerando as representações simbólicas hegemônicas e encontram privaçóes de seu direitos sociais devido ao racismo e classismo. Todavia, esses jovens se mobilizam e buscam a participação social.

Nós vimos que somos capazes, com a passagem, ela aumentou vinte centavos. Não quisemos, fizemos manifestações e conseguimos ganhar. Do mesmo jeito que conseguimos diminuir o valor da passagem, podemos fazer com várias outras coisas. [Por exemplo] mais hospitais, mais médicos e respeito [...] mais transporte público. [...]. Sem isso tudo [...] o final é isso [...] morte, destruição e violência. (Participante da oficina 2) 


\section{Discussão}

Evidencia-se que os jovens compreendem que as diferenças entre os territórios refletem na reprodução das desigualdades sociais. Portanto, é fundamental considerar os sujeitos, famílias e grupos sociais, a fim de identificar e compreender suas necessidades de saúde, as quais são atreladas às necessidades sociais, pois são geradas no contexto das relaçóes sociais ${ }^{20}$.

As diferenças e desigualdades se aprofundam ao considerar a chefia feminina dos lares no Brasil, que se caracterizam por apresentar renda familiar mais baixa comparativamente àquelas famílias chefiadas por homens ${ }^{1}$. Essa diferença explica aspectos das desigualdades sociais, que podem influenciar nas condiçóes de saúde desses homens jovens, dado a estreita relação da saúde com a reprodução social e o acesso aos serviços de saúde ${ }^{20}$.

As famílias chefiadas por mulheres são expressivas no território investigado, o qual tem alta concentração de pobres e negros ${ }^{21}$, coadunando com a representação identitária apresentada pelos participantes da pesquisa. Estudos destacam que, quanto maior a presença de negros em um local, mais os brancos fogem desses territórios ${ }^{22}$. Além disso, considerando a cidade de São Paulo, local do estudo, desde sua urbanização, foi criado um quadro de contradiçôes sociais, sendo a cidade organizada segundo a lógica do capital e voltada para as classes privilegiadas; segregação que se mantém, evidenciando que esses homens jovens estão à margem do Estado ${ }^{23}$. Os resultados do estudo confirmam o fato histórico brasileiro da abolição da escravatura à atualidade: os negros são segregados e têm acesso desigual aos serviços públicos disponíveis ${ }^{24}$.

A diferença também ocorre quando se leva em consideração a questão da educação desses homens jovens. A problemática apresentada pelos jovens na questão educacional é um fenômeno comum entre os jovens pobres ${ }^{25}$, não significando que a dinâmica de abandonarem os estudos seja uma situação irreversível, o que torna, inclusive, difícil de determinar o término da escolaridade ${ }^{26}$. Em relação aos que permanecem na escola, de acordo com a literatura, homens jovens negros com diploma universitário que trabalham não são beneficiados com salários equiparados aos demais ${ }^{27}$. Ademais, os jovens negros que estudam têm menos chance de ocupar posiçóes de destaque e maiores chances de perder tais postos de maior status social ${ }^{21}$.

Quando se trata da relação "nós” versus "eles", considerando a mídia como representante da estrutura social, em sua lógica, esses homens são apresentados como perigosos, reforçando o estereótipo encontrado na mídia brasileira de que o homem negro é pobre, bruto e violento ${ }^{28}$. É evidente que as midiatizaçốes e açôes policiais realizadas, por exemplo, com os "rolezinhos" das periferias trazem a marca da discriminação aos homens pobres negros. Considera-se que o racismo interseccionado com a classe social leva esses jovens a desvantagens sociais e a estereótipos de que eles estão sempre envolvidos com criminalidade e violência ${ }^{29}$, o que leva a sociedade a ter medo deles.

É dentro desse contexto de contradiçôes, precariedades e exclusões que os homens jovens negros constroem suas identidades em processos conflitivos desenvolvidos ao longo da vida ${ }^{30}$. Essas identidades são construídas com os símbolos estabelecidos da estrutura social e se disseminam no consenso do mundo social ${ }^{31}$; carregam os traços dos grupos sociais que os produziram, refletindo interesses sociais e modos de vida ${ }^{30}$. 
Assim, os homens jovens negros pobres constroem suas masculinidades considerando os valores hegemônicos marcados pelo consumo e individualização.

Os espaços de performance de masculinidades desses jovens da periferia são estereotipados, associados pelos que estão "de fora" e introjetados por eles próprios, muitas vezes, às dimensões da criminalidade e violência. Tomando-se uma das categorias sociais mais poderosas na atribuição de estereótipos para os jovens de periferia - os policiais -, observa-se a introjeção de tais estereótipos por parte dos próprios jovens, enquanto grupo social, pela heteronomeção que fazem os policiais sobre eles. Logo, o território e a performance das masculinidades dos jovens da periferia são indissociáveis tanto das condições socioeconômicas, da violência e da segragação a que estão expostos quanto do contínuo reforço de grupos sociais que os rotulam e criminalizam seus comportamentos e identidades, em um processo que retroalimenta sua exclusão social e acarreta importantes impactos para a Saúde Pública em termos individuais e populacionais.

As análises do material empírico vão ao encontro da história dos direitos, nos âmbitos político e social, os quais não foram garantidos aos negros, no momento da instauração dos direitos. Portanto, o quesito raça/cor aprofunda a diferença ao acesso dos homens/mulheres negros aos direitos sociais, ainda na contemporaneidade, quando tomamos a historicidade dos negros e o racismo no Brasil ${ }^{29,32}$. Assim, esses homens jovens negros encontram na estrutura social uma dinâmica de situaçóes de desigualdade e segregação ${ }^{21}$ e marginalização, que constituem parte importante da produção e reprodução de suas identidades.

\section{Considerações finais}

A análise das experiências dos homens jovens negros deste estudo revelam sistemas de desvantagens sociais marcadas por classe social, raça/cor, gênero e local de moradia. Nesse sentido, os determinantes sociais e os marcadores sociais da diferença entrelaçam-se, configurando desigualdades sociais e diversas formas de opressão vividas por esses jovens em suas práticas cotidianas.

Ser pobre, negro e morador periférico caracteriza-se, assim, como condição que potencializa a violação de direitos sociais, como os relativos à participação social, ao acesso à cidade e aos cuidados de saúde, revelando o processo histórico no qual são instituídas e perpetuadas as múltiplas desigualdades por eles vividas.

A análise, segundo referencial da interseccionalidade, apontou que os padrôes determinados pela estrutura social e as representaçôes simbólicas hegemônicas influenciam de modo sinérgico na construção das masculinidades dos homens jovens. Por um lado, o consumo de bens que remetem aos símbolos do poder masculino, valorizados por esses jovens, reproduz os critérios de exclusão vigentes na sociedade, na medida em que apenas aqueles que possuem condiçóes ou criam meios para adquiri-los desfrutam de poder e prestígio no grupo, pois encarnam um tipo de masculinidade ideal, desejada por seus congêneres. Por outro lado, o processo de exclusão social que lhes é imposto, assentado nas diferenças de raça/cor, gênero e local de moradia os fazem, frequentemente, vítimas da ação violenta de policiais, pois são considerados, socialmente, "vagabundos" e "perigosos". 
Com base nas experiências vividas por esses homens jovens, ficou evidente que eles compartilham desvantagens sociais que não se reduzem a um único marcador social da diferença, mas vários, que se entrelaçam e atuam de forma complexa na produção das desigualdades. Entende-se que a não hierarquização dos marcadores sociais da diferença permite o mapeamento das disparidades sociais e suas complexas aticulaçóes com a saúde e que análises que reduzem tais desigualdades a um único sistema classificatório, seja classe, gênero ou raça/cor, são inadequadas para compreender as várias dimensóes que as compóem, como a política, a econômica e os recursos que estão em jogo, conformando e influenciando as posiçốes sociais e as experiências dos sujeitos na sociedade.

A análise das experiências dos jovens expressas nas oficinas nas quais participaram mostra que estes fazem uma leitura crítica pontual da realidade vivida, indicando os estereótipos pejorativos que lhes são atribuídos pela mídia, pelos policiais e por moradores externos ao território. Da mesma forma, apontam os processos de exclusão internos ao grupo, como quando não compartilham do gosto musical afeito à maioria. Destaca-se que os processos opressivos de classe e raça/cor, fomentadores das desigualdades sociais e de saúde, são percebidos de forma aguda. Mas, embora o modo de superá-las seja alvo de consideraçóes, que passa pela mobilização popular, isso não garante a possibilidade de influir no destino de exclusão social e marginalização a que estarão submetidos.

A partir desse quadro, tem-se o desafio de criar politicas sociais e de saúde envolvendo os jovens, pois estes precisam ser ouvidos e chamados a participar na identificação de soluçôes para superar as iniquidades sociais e de saúde por eles vivenciadas.

\section{Contribuições dos autores}

Elda de Oliveira participou da concepção e delineamento do trabalho, da discussão dos resultados e da redação do manuscrito. Márcia Thereza Couto participou da concepção e delineamento do trabalho e da revisão crítica de seu conteúdo. Marco Antônio Alves Sepavich participou da discussão dos resultados e da redação do manuscrito. Olinda do Carmo Luiz participou da discussão dos resultados e da revisão crítica do conteúdo. Todos os autores participaram da aprovação da versão final do manuscrito.

\section{Agradecimentos}

Ao Programa de Incentivo à Atração de Pós-Doutorandos (PIAPD), da Pró-Reitoria de Pesquisa da USP - vigência 2018 -, e ao Programa Nacional de Pós-Doutorado (PNPD)/Capes, cota do Programa de Pós-Graduação em Saúde Coletiva, bolsa número 88882.315585/2019-01.

\section{Direitos autorais}

Este artigo está licenciado sob a Licença Internacional Creative Commons 4.0, tipo BY (https://creativecommons.org/licenses/by/4.0/deed.pt_BR).

\section{(cc) BY}




\section{Referências}

1. Programa das Naçốes Unidas para o Desenvolvimento - PNUD. Desenvolvimento humano para além das médias. Brasília: PNUD, IPEA, FJP; 2017.

2. Donkin A, Goldblatt P, Allen J, Nathanson V, Marmot M. Global action on the social determinants of health. BMJ Glob Health. 2017; 3 Suppl 1:e000603.

3. Nygren KG, Olofsson A. Intersectional approaches in health-risk research: a critical review. Sociol Compass. 2014; 8(9):1112-26.

4. Hankivsky $\mathrm{O}$, Christoffersen A. Intersectionality and the determinants of health: a Canadian perspective. Crit Public Health. 2008; 18(3):271-83.

5. Hankivsky O. Women's health, men's health, and gender and health: implications of intersectionality. Soc Sci Med. 2012; 74(11):1712-20.

6. Hankivsky O, Doyal L, Einstein G, Kelly U, Shim J, Weber L, et al. The odd couple: using biomedical and intersectional approaches to address health inequities. Glob Health Action. 2017; 10 Suppl 2:1326686.

7. Bowleg L. The problem with the phrase women and minorities: intersectionalityan important theoretical framework for public health. Am J Public Health. 2012; 102(7):1267-73.

8. Hankivsky O, Reid C, Cormier R, Varcoe C, Clark N, Benoit C, et al. Exploring the promises of intersectionality for advancing women's health research. Int $\mathrm{J}$ Equity Health. 2010; 9(1):5.

9. Bauer GR. Incorporating intersectionality theory into population health research methodology: challenges and the potential to advance health equity. Soc Sci Med. 2014; 110:10-7.

10. Cho S, Crenshaw KW, McCall L. Toward a field of intersectionality studies: theory, applications, and praxis. Signs. 2013; 38(4):785-810.

11. Brah A. Diferença, diversidade, diferenciação. Cad Pagu. 2006; (26):329-76.

12. Conell R. Gênero em termos reais. São Paulo: nVersos; 2016.

13. Schraiber LB, Gomes R, Couto MT. Homens e saúde na pauta da Saúde Coletiva. Cienc Saude Colet. 2005; 10(1):7-17.

14. Soares CB, Oliveira E, Souza GC. Pesquisa-ação: oficinas emancipatórias como instrumento de pesquisa em representaçóes cotidianas. Rev Sociol Rede. 2015; 5(5):12-26.

15. Weller W. A atualidade do conceito de gerações de Karl Mannheim. Soc Estado. 2010; 25(2):205-24.

16. Feixa C, Leccardi C.O conceito de geração nas teorias sobre juventude. Soc Estado. 2010; 25(2):185-204.

17. Carlos AFA. A metrópole de São Paulo no contexto da urbanização contemporânea. Estud Av. 2009; 23(66):303-14.

18. Oliveira E, Soares CB, Silva JA. Pesquisa-ação emancipatória com jovens escolares: relato de experiência. Rev Gauch Enferm. 2016; 37(3):e62059.

19. Winker $G$, Degele N. Intersectionality as multi-level analysis: dealing with social inequality dealing with social inequality. Eur J Women's Stud. 2011; 18(1):51-66.

20. Moraes PA, Bertolozzi MR, Hino P. Percepçóes sobre necessidades de saúde na Atenção Básica segundo usuários de um serviço de saúde. Rev Esc Enferm USP. 2011; $45(1): 19-25$. 
21. Lima M. "Raça" e pobreza em contextos metropolitanos. Tempo Soc. 2012; 24(2):234-54.

22. Gilbert KL, Ray R, Siddiqi A, Shetty S, Baker E, Elder K, et al. Visible and invisible trends in black men's health: pitfalls and promises for addressing racial, ethnic, and gender inequities in health. Annu Rev Public Health. 2016; 37:295-311.

23. Scarlato FC, Alves GA. São Paulo: uma metrópole em constante mutação. Bol Paul Geogr. 2018; 100:156-72.

24. Heringer R. Desigualdades raciais no Brasil: síntese de indicadores e desafios no campo das políticas públicas. Cad Saude Publica. 2002; 18 Supl:57-65.

25. Carrascal REE, Rotela MM. Influencia de la familia en el proceso educativo de los menores del barrio Costa Azul de Sincelejo (Colombia). Investig Desar. 2009; $17(1): 84-105$.

26. Sposito MP, Souza R, Silva FA. A pesquisa sobre jovens no Brasil: traçando novos desafios a partir de dados quantitativos. Educ Pesqui. 2018; 44:e170308.

27. Magno LD, Paim JS. Dos clamores das ruas aos rumores no Congresso: uma análise da conjuntura recente da saúde no Brasil. RECIIS. 2015; 9(4):1-14.

28. Araujo JZ. Identidade racial e estereótipos sobre o negro na TV brasileira. In: Guimarães ASA, Huntlet L, organizadores. Tirando a máscara: ensaios sobre o racismo no Brasil. São Paulo: Paz e Terra; 2000. p. 77-95.

29. Guimarães ASA. Apresentação. In: Huntley L, Guimarães ASA, organizadores. Tirando a máscara: ensaios sobre o racismo no Brasil. São Paulo: Paz e Terra; 2000. p. 17-30.

30. Connell R, Pearse R. Gênero: uma perspectiva global. São Paulo: nVersos; 2015.

31. Bourdieu P. A distinção: critica do julgamento. 2a ed. Porto Alegre: Zouk; 2017.

32. Silva NV. Extensão e natureza das desigualdades raciais no Brasil. In: Huntley L, Guimarães ASA, organizadores. Tirando a máscara: ensaios sobre o racismo no Brasil. São Paulo: Paz e Terra; 2000. p. 33-52. 
This article analyzes the experiences of young men living in the city outskirts regarding social inequalities and their impacts on the health-disease-care production process. The empirical material that supports the intersectional analysis was produced with a qualitative methodology of researchaction based on workshops, a group technique with participatory investigations. A total of 21 men and five women aged between 15 and 17 years who studied at a neighborhood public school of the Brazilian city of São Paulo, state of São Paulo, participated in the study. The results highlight that young men share intertwined race-color, class, gender, and generation disadvantages that act in a complex way in the production of social and health inequalities. Therefore, analyses that restrict inequalities to a single classificatory system — class, gender, or race/color — are inadequate to understand the various dimensions that comprise them.

Keywords: Intersectionality. Teenager. Masculinity. Public health. Social inequity.

El artículo analiza las experiencias vividas por hombres jóvenes de la periferia con relación a las desigualdades sociales y a sus impactos en el proceso de producción de la salud-enfermedad-cuidado. El material empírico que da soporte al análisis interseccional fue producido por la metodología cualitativa de investigación-acción a partir de talleres, técnica grupal en investigaciones participativas. Participaron 21 hombres y cinco mujeres con edades entre los 15 y 17 años que frecuentaban una escuela pública de la región periférica del municipio de São Paulo (Estado de São Paulo), Brasil. Los resultados subrayan que los hombres jóvenes comparten desventajas de raza-color, clase, género y generación que se entrelazan y actúan de manera compleja en la producción de las iniquidades sociales y de la salud. Por lo tanto, análisis que reducen las desigualdades a un único sistema clasificatorio, sea de clase, género o raza/color, son inadecuadas para comprender las varias dimensiones que las componen.

Palabras clave: Interseccionalidad. Adolescente. Masculinidad. Salud pública Iniquidad social. 